\title{
Thermography in the Investigation of Gilding on Historical Wall Paintings
}

\author{
by M. Poksińska*, A.Cupa** and S. Socha-Bystroń
}

\author{
*Nicholas Copernicus Univesity, Faculty of History, Department for the History of Art and Culture, Toruń, Poland \\ ** Nicholas Copernicus Univesity, Faculty of Fine Art, Poland
}

Keywords: infrared thermography, historical architecture, wall paintings

\begin{abstract}
New non-destructive methods are sought in the field of wall painting restoration in order to evaluate the state of preservation of original painting workout covered with whitewash and over-paintings. The authors of this article used thermography to investigate gilding covered by paint layers. The efficiency of thermographic methods was evaluated in the context of the state of preservation (deterioration) and range of the gilded fragments. At the beginning models of multi-layer paint structure were investigated by means of active and passive thermography. On a layer of plaster two models of gilding were prepared in the form of stripes and circles (to imitate the nimbuses). Some areas of gilding were subject to mechanical deterioration. Next whitewash and polychromy were put. The aim of this experiment was to determine optimal measuring conditions for thermography and the feasibility of evaluation of the state of deterioration of gilding. A Reytheon Controll IR 2000B camera was applied.

The results allowed to localize gilded areas under the layers of whitewash and polychromy and to distinguish well preserved areas from those deteriorated. Therefore it can be assumed that the thermographic method can provide rich information on original wall paintings, which was actually confirmed by examination of historical monuments.
\end{abstract}

\section{Introduction}

At the investigation of historical architecture valuable painting workout is often discovered. In the European art, Romanesque and Gothic wall paintings are often covered with over-painting or whitewash. The joy of discovery of ancient painting is sometimes accompanied with the lack of technical means that would allow to determine their content and state of preservation. The outer Renaissance or Baroque decoration cannot be removed as they also present historical value.

Therefore non-destructive methods are sought in order to penetrate inside a multi-layer structure down to the oldest painting workout. Much hope is associated with thermographic methods and the have already found an important position in the conservation practice. Recently they have been applied among others to the evaluation of the state of preservation of sculptures, wall paintings and structure of ancient architecture [1,2,3 ].

A research group from Nicolaus Copernicus University in Torun in cooperation with the Polytechnic of Łódź have for several years realized a programme of implementation of thermographic methods for the sake of conservation of works of art [ 4 ].

\section{The use of thermographic methods to the investigation of historical wall paintings}

The most important and the most difficult task in the area of monuments investigation by thermographic methods is a correct interpretation of the received thermograms. Having this in mind, a long-lasting cycle of basic research was planned. One of the stages has been presented in the present work.

\subsection{Models of multi-layer polychromy and the conditions of thermographic measurements}

After the expectations as of thermographic methods in conservation have been verbalized, appropriate models of multi-layer polychromy have been prepared. The structure and composition was compatible to Gothic wall paintings covered with whitewash and over-painting. With the use of static and dynamic thermography we tried to solve the question of identification of the location and diversification of composition of the oldest polychromy covered with subsequent paint layers [ 5 ].

A method of heat wave was used - energy was submitted to the investigated object in the form of radiation of the frequency $\mathrm{f}=0,5 \mathrm{~Hz}$. A $2 \mathrm{~kW}$ heat generator was applied. Three hundred pictures were recorded at a frequency $T=0,5 \mathrm{~s}$ and subjected to frequency analysis. For every coordinates of the picture harmonic signals were determined, including the amplitude and phase image for the frequency of energy excitation equal $\mathrm{f}=0,5 \mathrm{~Hz}$. A Raytheon Controll IR 2000B camera was used in the range from 7 to $14 \mu \mathrm{m}$ and 240-320 pixel resolution.

The thermographic analysis revealed that there exists a possibility of picture recording from in-depth of the paint layer structure. Primary layers covered with whitewash were clearly legible and provided a diversified image depending on the pigments used [6]. 


\subsection{Investigation of gilding covered with whitewash and polychromy}

The next stage of the research programme comprised the evaluation of recording of gilding covered with over-painting. Another model was prepared in order to reflect the technique of Gothic polychromy with the use of pigments and media typical for that period. [ 5 ]. Except for commonly used gold, silver and brass foil also aluminium foil was applied. Also in this case it appeared feasible to confirm the presence of foil and determine its location under a layer of whitewash. Moreover, different image was obtained for different foils. Also the presence of glaze (resin protection film on the foil surface changing its colour) was legible. The area of foil is clearly distinguishable from the substrate and whitewash but unfortunately the subsequent over-painting perturbed the image. Such a concept of model where foil fragments were placed in direct contact appeared not to be a good solution.

Further research with the use of the third laboratory model, Fig. 1, concerned the evaluation of the state of preservation and the range of gilding under whitewash and polychromy. Taking into account previous experiences, a model on sandstone substrate was constructed, Fig. 2a and gilding was applied in separate circles (which imitated nimbuses of saints from Gothic paintings). Only two types of foil were used: gold and silver. Circles of intact and mechanically deteriorated foil (gold or silver) were applied in pairs Fig.2d. Next the gilded areas were covered with whitewash and polychromy (glazing and covering paint)

As above, for static analysis a. Raytheon Controll IR 2000B camera was used. The model was heated by means of two $1000 \mathrm{~W}$ halogen lamps from the distance of $1 \mathrm{~m}$. The recorded images were analysed with the use of ThermoScope software. Further tests were performed by a dynamic method.

A

B C D

E

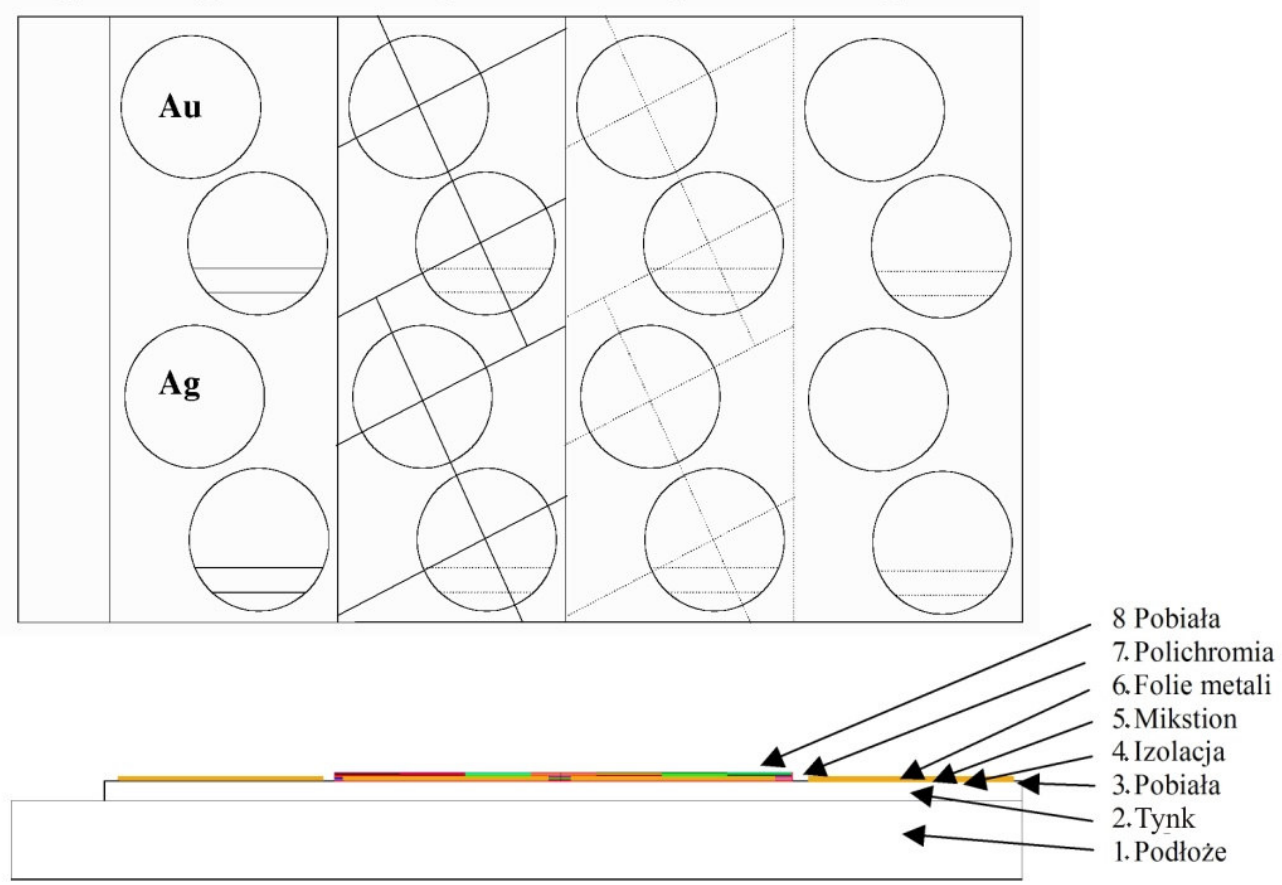

Fig. 1. Design of a model of a multi-layer painting structure

A - sandstone substrate,

$\mathrm{B}$ - plaster covered with whitewash and a circle of metal foil,

C - a polychromy layer upon gilding,

D - gilding covered with whitewash and polychromy,

E - gilding covered with a whitewash layer.

1.Substrate. 2.Plaster. 3.Whitewash. 4.Isolation. 5.Glaze. 6.Metal foil. 7.Polychromy. 8. Whitewash 

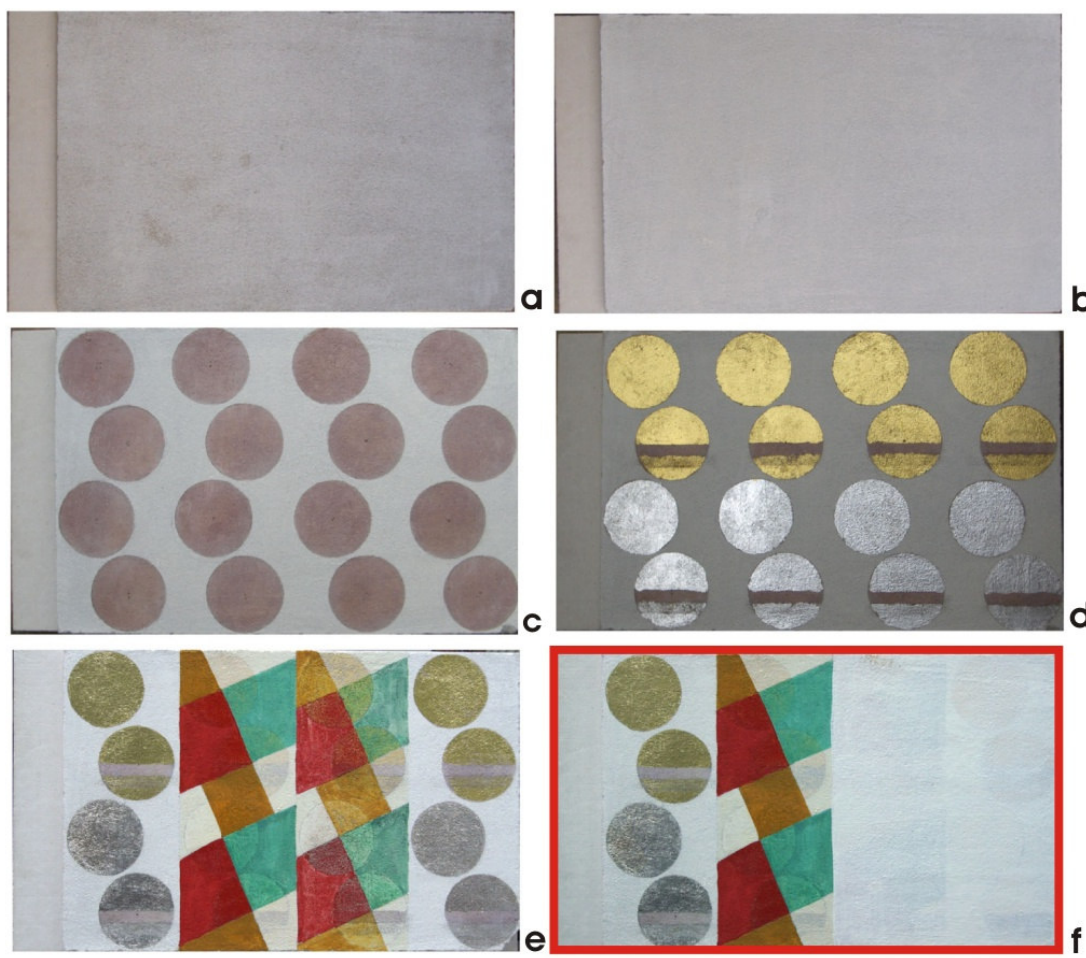

Layer 2 -

calcareous-sandy

b plaster on sandstone substrate,

Layer 3 whitewash,

Layer $4 \quad$ isolation under gilding,

Layer 6 - gold and silver foil, deteriorated in the lower part of the circle,

Layer 7 - central part of the model covered with whitewash and polychromy,

Layer 8 whitewash on the left side of the model.

Fig. 2. The stages of model construction, layers marked as on model cross-section

\subsubsection{Experimental results}

The thermograms obtained by static method Fig. 3 show the usefulness of the method in identification of gilding under a whitewash layer. The deteriorated fragments are also legible Fig.3d. The character of deterioration is visible on the recorded thermographic images.
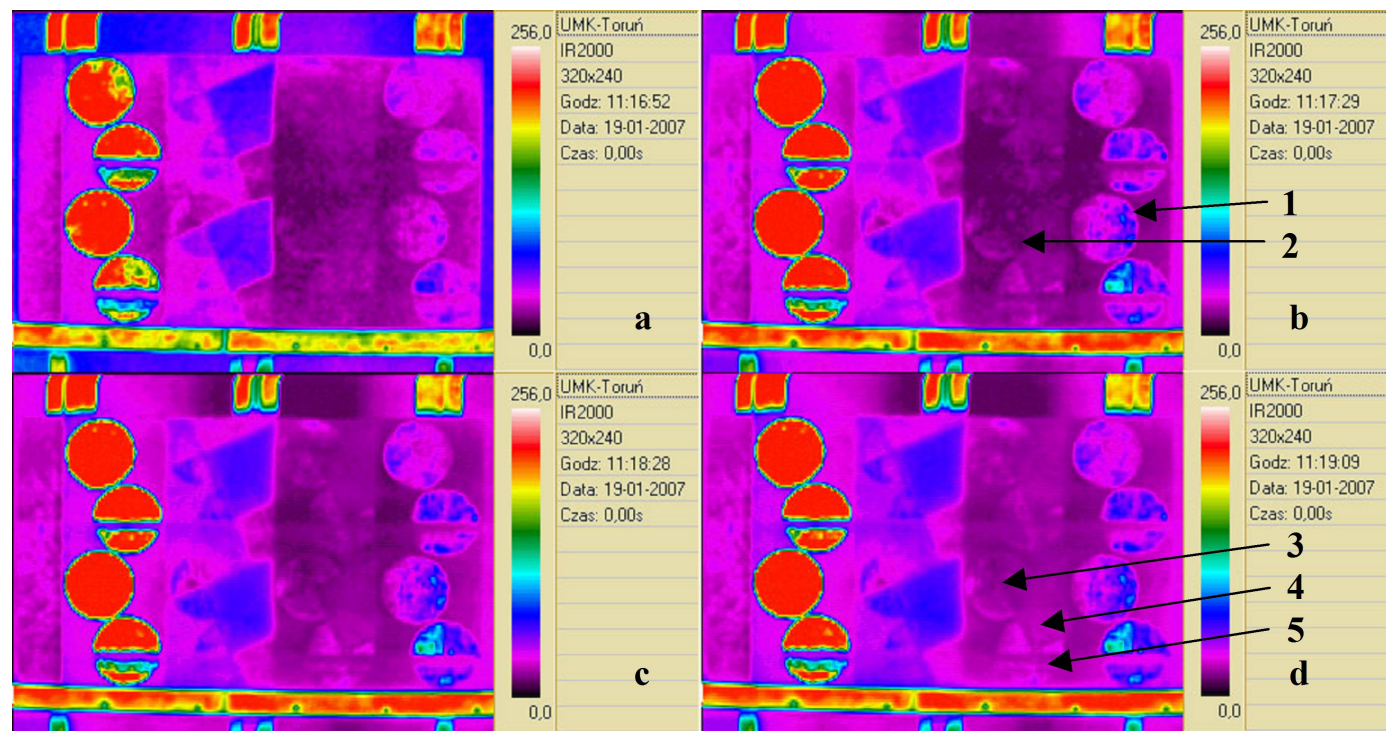

Fig. 3. Thermographic images recorded in course of heating of the model by a dynamic method.

The location of metal foil is visible under whitewash (1). Gilding covered with whitewash (2) and with whitewash and polychromy (3) was also recorded. In the area of green the image of gilding is less visible than in the area of red (4). The zones of deteriorated gilding are visible on the thermograms also under a layer of whitewash and polychromy (5)

To sum up - the results obtained confirmed the applicability of thermographic methods in the location of gilding under over-painting. In the conservation practice and for historical reasons it would be most useful if thermographic methods could be applied to investigate the polychromy of Gothic sculptures. They were often 
gilded and the gilding was either performed with the use of gold foil or with silver foil and glazing. The results presented above might be used for interpretation of such layers but the spatial form of the sculpture appeared to be an obstacle which was evident after the first filed trails performed.

\section{Examples of investigation of historical objects}

After every stage of investigation with the use of specially prepared models of multi-layer polychromy, testing was carried out on historical Gothic architecture. Gothic wall paintings covered with Renaissance and Baroque over-painting and whitewash were examined as well as wooden and stone sculptures.

At the experimental conditions as described above, information was obtained on the deterioration of plasters and polychromy, over-painting and diversification of painting materials .

Thermography showed to be a satisfactory method in searching for polychromy and gilding under a layer of whitewash, which can be seen from the following figures Fig 4, 5, 6 .
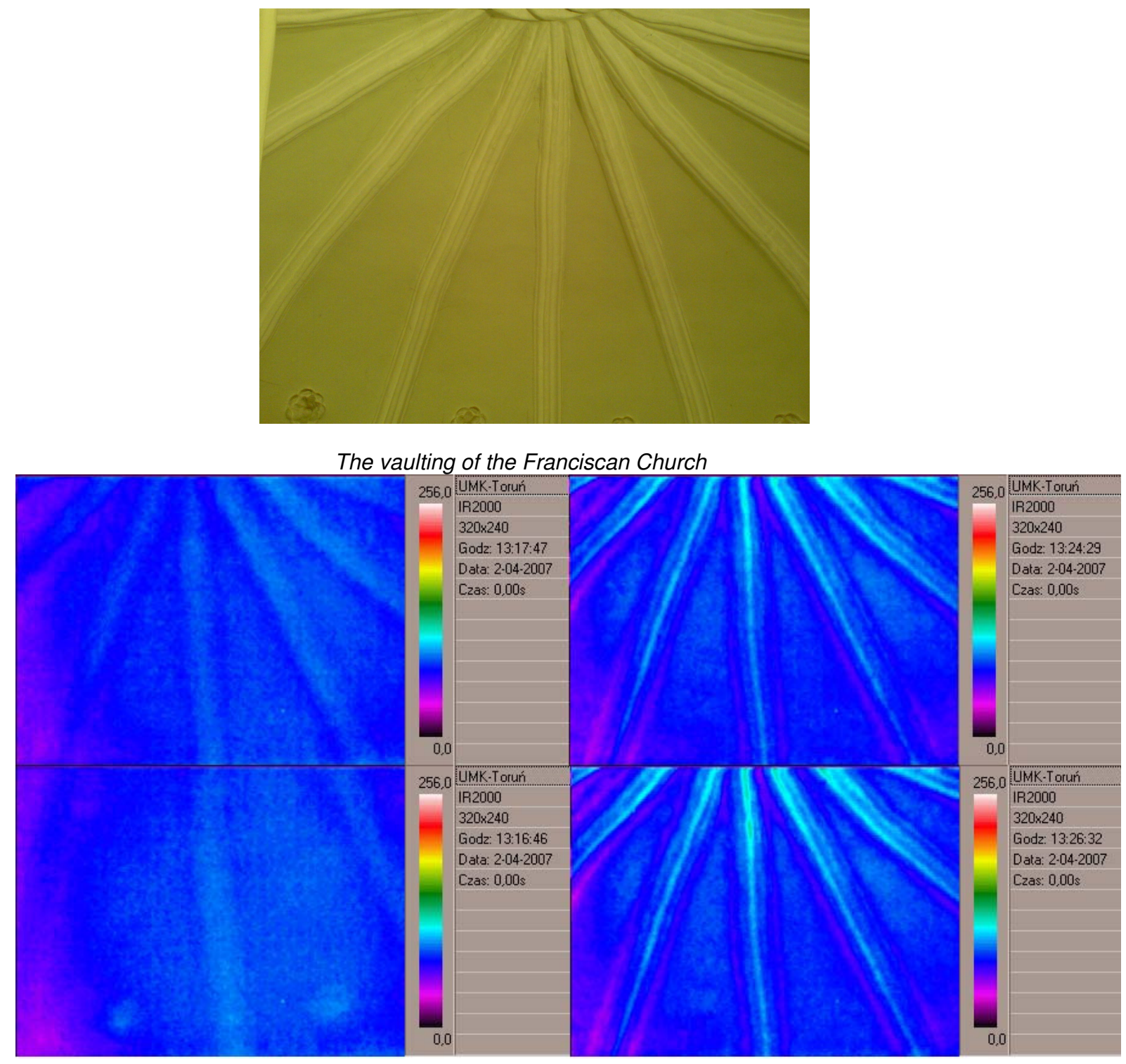


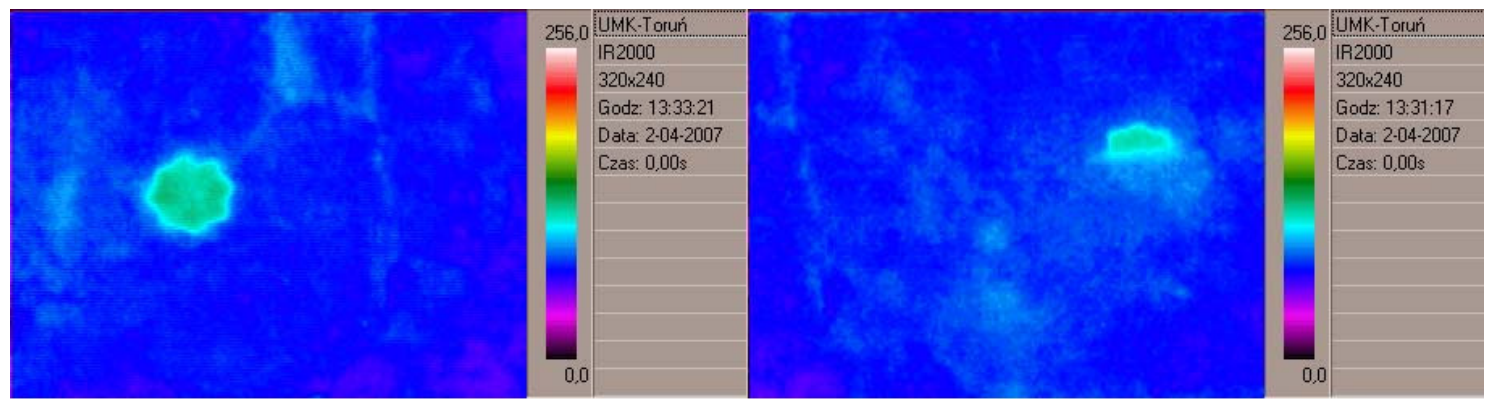

Fig. 4. Thermographic measurements on the vaulting of the Franciscan Church in Włocławek (Poland). Images of the ribs recorded with no heating provision $(a, b)$ and after heating $(c, d)$. The two latter pictures revealed the presence of stars under whitewash $(a, b)$
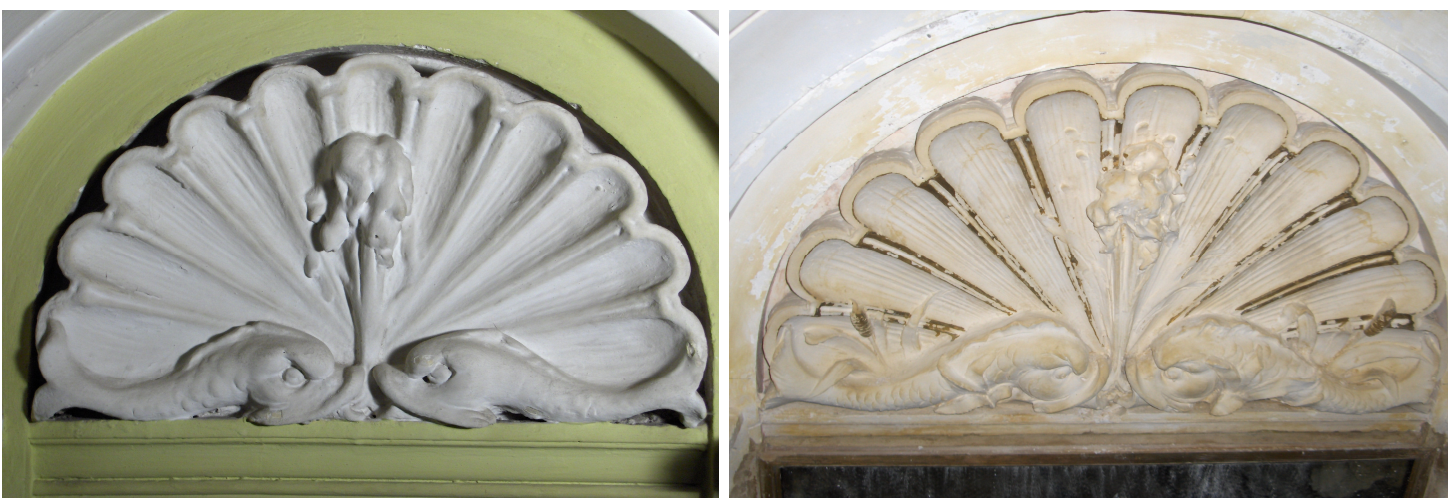

Fig. 5. Stuccowork in Ciechocinek (Poland). On the left side picture a fragment covered with white wash, on the right side - gilding uncovered after cleaning

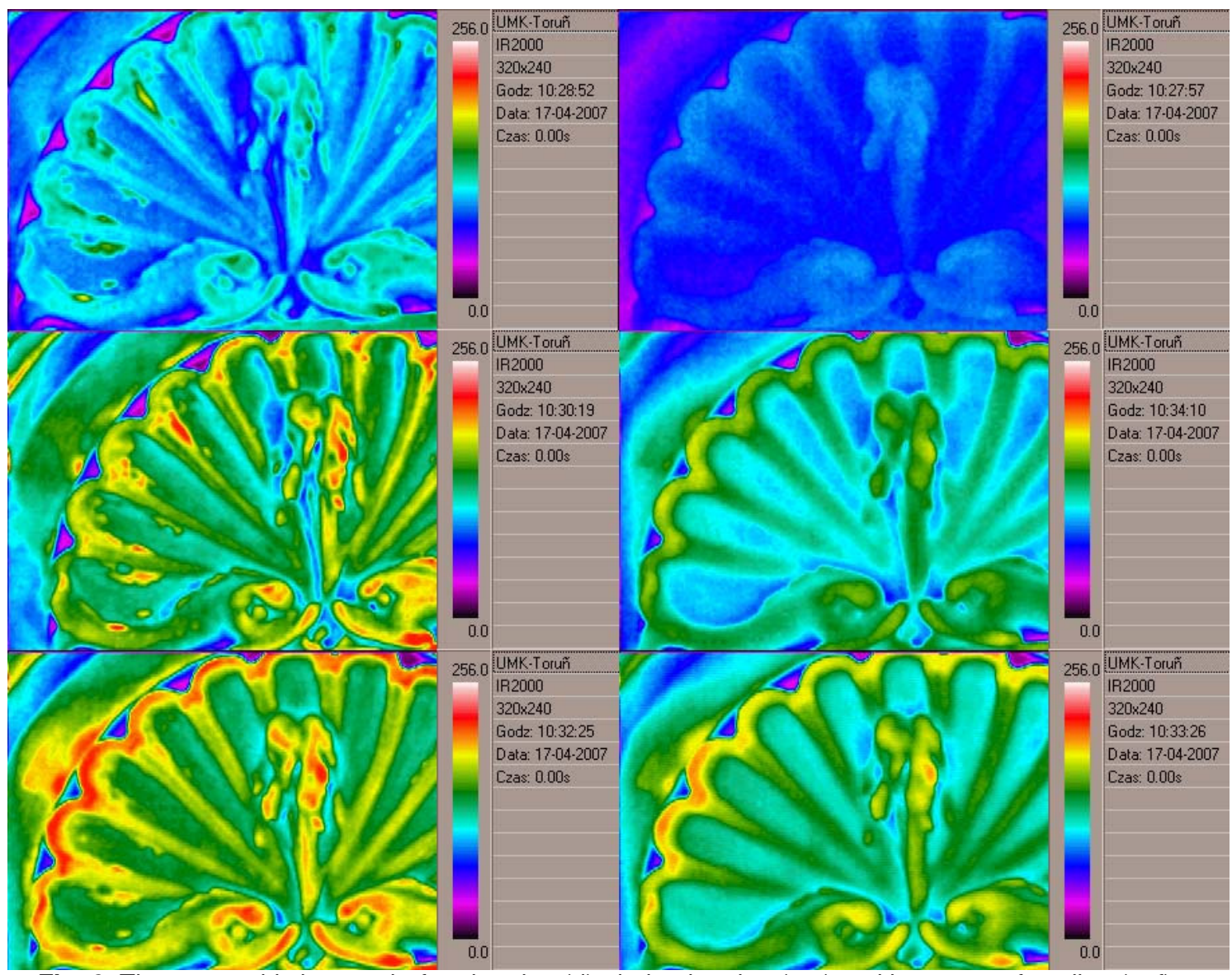

Fig. 6. Thermographic images before heating $(d)$, during heating $(a-c)$ and in course of cooling $(e, f)$ 


\section{Resume}

The nature of the thermographic method makes it particularly useful for the investigation of historical paintings and architecture. Thermography responds to the tasks in combination with other non-destructive methods applied in monuments restoration as e.g. Optical Coherence Tomography, Electron Paramagnetic Resonance, X-ray Fluorescence, LIBS - Laser Induced Breakdown, LIF - Laser Induced Fluorescence and other classical photographic methods in various electro-magnetic range [ 7 ].

It provides quick information on the state of preservation and technical structure of the object. It allows to compare the same material in different areas of the painting workout and to distinguish between materials of similar colour but different chemical composition. It is irreplaceable at the examination of architecture where it reveals the traces of changes and repairs as well as polychromy under whitewash. As results from the tests performed on models gilding and polychromy can be detected only if the layer of whitewash and over-painting is of low thickness.

The models of reference polychromy revealed advantages and disadvantages of the thermographic method and can be considered as reference for interpretation of wall paintings and architectural polychromy.

\section{REFERENCES}

[1] J.C.Candore, G.Szatanik, J.L.Bodnar, V. Detalle, P.Grossel. Infra-red photothermal thermography: A tool of assistance for the restoration of murial paintings? (in:) QIRT 2006, Book of Abstracts, Padova 2006 (125126).

[2] L. Ibos, M.L. Youcef, A.Mazioud, S. Datcu, Y.Candau. Non-destructive testing of Building walls using active infrared thermography (in:) QIRT 2006, Book of Abstracts, Padova 2006 (123-124).

[3] N.Ludwig, E.Rosina, Restoration mortars at IRT: optical and hygroscopic properties of surfaces (in:) QIRT 2006, Book of Abstracts, Padova 2006 (139-140).

[4] B. Więcek, M. Felczak, M. Poksińska, A. Cupa, Wielospektralne badania zobrazowań zabytków architektury.Cz.1. System zobrazowań. Konferencja Termografia i Termometria w Podczerwieni, Łódż 2004, s.387-393.

[5] M.Poksińska, M.Nowocińska, B.Więcek, Models of Multilayer Structures of Gothic Polychromy and their Application to the Development of new Research Techniques.(in:) The High Castle of Malbork, MalborkToruń-Łódź 2006(227-230).

[6] B. Więcek, M. Felczak. The Thermographic Method as a new Research Tool and its Application of Works of Art (in:) The High Castle of Malbork, Malbork-Toruń-Łódź 2006(231-234).

[7] Techniki analityczne w konserwacji zabytków, Seminarium i warsztaty, Gdańsk 2006. 